\title{
O DIREITO À CIDADE: URBANIZAÇÃO EXCLUDENTE E A POLÍTICA URBANA BRASILEIRA
}

\author{
Danila M. de Alencar Battaus \\ Instituto de Arquitetura e Urbanismo, Universidade de São Paulo, São Paulo, SP; \\ Universidade de Marília, Marília, SP.Brasil.E-mail<dbattaus@unimar.br > \\ Emerson Ademir B. de Oliveira \\ Universidade de São Paulo (USP), São Paulo, SP; Universidade de Coimbra,Portugal; \\ Universidade de Marília, Marilia, SP. Brasil. E-mail <borgesdeoliveira@usp.br>
}

http://dx.doi.org/10.1590/ 0102-6445081-106/97

A pluralidade enquanto essência da cultura brasileira, verificada na configuração do território nacional e nos costumes impressos na paisagem, pouco se faz notória nos processos de urbanização, especialmente em cidades de médio e grande porte. Nesses centros, é recorrente a prática da organização espacial a partir das condições socioeconômicas de seus habitantes, caracterizando-se o solo urbano como uma mercadoria, suscetível às façanhas dos agentes produtores da cidade.

Essa distribuição explicitamente desigual da população no território urbano agrava-se com a ocorrência de fenômenos frequentes, cujos desdobramentos implicam a perda da qualidade de vida urbana. O significativo número de vazios urbanos que geram lacunas na ocupação do solo e descontinuidade do sistema viário e das redes de infraestrutura e, em contraposição, o adensamento desordenado de algumas regiões, são algumas referências desses fenômenos.

Diante desse cenário, observa-se a fragilidade do Estado brasileiro em seus intentos de garantir a todo cidadão o "direito à cidade". A despeito das preocupações inéditas de nossa Constituição, que levaram ao desenho dos artigos 182 e 183, 
imbuídos da missão de redirecionar a política urbana, e do Estatuto da Cidade que daí decorreu, ao cabo sobreleva-se a necessidade de maiores esforços na implementação dos instrumentos existentes.

$\mathrm{O}$ direito à cidade, enquanto um direito metaindividual, sublocado à terceira dimensão dos direitos, e com amparo constitucional, é, fundamentalmente, um direito que os cidadãos têm a uma cidade hígida, a um ambiente harmônico e equilibrado e a um local que proporcione dignidade à pessoa.

Nessa linha, viabilizar o direito à cidade é também dar efetividade à dignidade do indivíduo, melhorando, assim, a qualidade de vida dos cidadãos. Propõe-se, portanto, analisar em que medida esse direito, que possui amparo constitucional, tem ganhado contornos práticos no cotidiano urbano. E quais as ranhuras, numa análise geral, que ainda impedem melhores resultados a instrumentos teoricamente tão hábeis quanto aqueles que iluminam o Estatuto da 82 Cidade.

\section{0 direito à cidade e o processo de urbanização nas cidades brasileiras}

Notadamente influenciada por uma perspectiva intergeracional, como as Constituições portuguesa, de 1976, espanhola, de 1978, e alemã (de Bonn), de 1949, a nossa Carta Política traz o cerne do desenvolvimento humanitário. Isto é, uma nítida preocupação com a garantia do desenvolvimento nacional (art. $3^{\circ}$, II) a partir da livre iniciativa (art. 170, caput) e da propriedade privada (art. 170, II), mas sem perder de vista a necessidade de fazê-lo com embasamento na pessoa digna (art. $1^{\circ}$, III), na valorização do trabalho humano (art. 170, caput) e na função social da propriedade (art. 170, III).

A confecção e a leitura da norma fundamental denotam, resumidamente, uma perspectiva de que o desenvolvimento econômico brasileiro é imprescindível, mas desde que não seja feito sem preocupações com o social que o escora. 
Noutra leitura, vislumbra-se que, nos idos contemporâneos de nossa Constituição, há uma preocupação com todos os segmentos e dimensões de direitos fundamentais, perpassando pelos típicos direitos de defesa, que afrontaram o Estado absoluto, pelos direitos prestacionais, que exigiram do Estado uma postura positiva em algumas temáticas, até os direitos de cunho coletivo, visualizados da perspectiva da sociedade considerada como um todo. Mesmo alguns chamados direitos de quarta dimensão se fazem presentes entre nós, como o desenvolvimento da cidadania e a presença de instrumentos de democracia direta (Bonavides, 2002, p. 526).

A ideia de dimensões dos direitos fundamentais, advirta-se, não se presta a apontar simples rupturas, mas sim um processo de continuidade. Daí o fato de que nossa Constituição soube abrigar todas as suas dimensões, sem que houvesse entre elas qualquer predileção à exclusão recíproca. É o que ensina, nessa linha, Sarlet (2001, p. 56):

O breve olhar lançado sobre as diversas dimensões dos direitos fundamentais revela-nos que o seu processo de reconhecimento é de cunho essencialmente dinâmico e dialético, marcado por avanços, retrocessos e contradições, ressaltando, dentre outros aspectos, a dimensão histórica e relativa dos direitos fundamentais, que se desprenderam no mínimo, em grande parte - de sua concepção inicial de inspiração jusnaturalista.

Num primeiro momento, sob a égide do Estado liberal, viu-se o cidadão carente de proteção contra o Estado, para que este não se imiscuísse desarrazoadamente na vida daquele. Como aponta Andrade (1998, p. 43; grifo no original): "Aparecem, por isso, fundamentalmente, como liberdades, esferas de autonomia dos indivíduos em face do poder do Estado, a quem se exige que se abstenha, quanto possível, de 
se intrometer na vida social". Nesse sentido, destacam-se os direitos à vida, propriedade, liberdade e igualdade.

A segunda dimensão encontra seu amparo no Estado social, alterando o foco, não mais defendendo o indivíduo do Estado, mas utilizando o Estado para proteger o indivíduo. Nesse momento, sobreleva-se a ideia de que o desenvolvimento econômico e industrial não pode ter a si mesmo por fim, sem maiores preocupações com o ambiente social que lhe embasa, razão pela qual seu gatilho se dispara com a Revolução Industrial. Destinam-se, esses direitos, às vertentes trabalhistas, educacionais e sociais, em geral, "revelando uma transição das liberdades formais abstratas para as liberdades materiais concretas" (Sarlet, 2001, p. 51). Por essas características passam a ser conhecidos como "positivos" ou "direitos a prestações".

A terceira dimensão elucida a crescente de um novo tipo de direito e de uma nova vertente estatal: a inegável lógica de 84 que alguns direitos não pertencem a indivíduos considerados em sua individualidade, mas à sociedade como um todo ou, ao menos, parte dela. Emergem as tutelas difusas e coletivas, objetivadas a proteger os direitos metaindividuais, como o meio ambiente, a qualidade de vida, o patrimônio cultural e histórico e as relações de consumo.

A propósito, observa Sarlet (2001, p. 53):

A nota distintiva destes direitos da terceira dimensão reside basicamente na sua titularidade coletiva, muitas vezes indefinida e indeterminável, o que se revela, a título de exemplo, especialmente no direito ao meio ambiente e qualidade de vida, o qual, em que pese ficar preservada sua dimensão individual, reclama novas técnicas de garantia e proteção.

Esses direitos, de terceira dimensão, escorados em um suporte coletivo - povo, humanidade, sociedade - exterio- 
rizam o princípio da solidariedade, sem esquecer que a solidariedade já perfazia uma “dimensão ‘indimensionável' dos direitos económicos, sociais e culturais" (Canotilho, 2007, p. 387), mas que, certamente, ganharam novos contornos com a ascensão de uma preocupação mais latente com a socialidade.

Ora, comose denota dos próprios exemplos mencionados, muitos dos direitos metaindividuais se associam à própria vivência social, de forma a reproduzir qualitativamente a vida em sociedade. Nesse interim, desenvolve-se com lucidez o próprio direito à cidade, associado a um incremento da qualidade de uma vida humana e digna, a valorização do patrimônio cultural e social e até mesmo os noveis direitos à moradia e ao transporte público, direitos sociais ${ }^{1}$ implantados no artigo $6^{\circ}$ de nossa Constituição, respectivamente pelas Emendas $n^{\circ} 26 / 2000$ e n $^{\circ} 90 / 2015$.

E o fez de forma ainda mais específica nos artigos 182 e 183 da norma fundamental, a tratarem da política urbana, e sobre o qual nos debruçaremos com maior destreza. É oportuno refletir sobre o processo de urbanização das cidades brasileiras, sobretudo a partir do respaldo da política urbana anunciada nos referidos artigos constitucionais.

O Brasil é um país urbano, ou seja, ao longo das últimas décadas do século XX, os movimentos migratórios do ambiente rural para o urbano, nas cidades brasileiras, foram notórios. Em 2000, 81,2\% da população brasileira se encontrava em áreas urbanas, segundo Maricato (2001), e, no mesmo período, em seis metrópoles do Brasil, viviam cerca de 50 milhões de pessoas.

Duas de nossas maiores cidades têm extensão superior à de muitos países. Estão entre as maiores aglomerações do

\footnotetext{
1 "A qualidade de direitos fundamentais atribuída aos direitos sociais integra-se no espírito do 'instituto', que visa à defesa da dignidade das pessoas concretas e tem, nessa medida, uma expressão prática na garantia a cada indivíduo de um conteúdo mínimo de solidariedade social” (Andrade, 1998, p. 345).
} 
mundo. Aproximadamente $80 \%$ dos moradores de favelas estão em nove regiões metropolitanas. Apesar das dimensões desses dados, não temos, no Brasil, nenhuma política institucional para as metrópoles (Maricato, 2001, p. 78).

A ocupação do território dessas cidades caracteriza-se sobretudo por processos complexos, nos quais a distribuição populacional ocorre no contexto socioespacial. Isto posto, as camadas sociais habitam setores urbanos de acordo com o poder aquisitivo. Na visão de Carlos (1994, p. 47), "a discussão do valor do espaço nos remete à ideia do espaço-mercadoria”, facultado às definições do mercado imobiliário quanto ao seu valor. Assim, as regiões mais urbanizadas, abastecidas por todas as redes de infraestrutura urbana e dos equipamentos que prestam os serviços urbanos, fatalmente constituirão a mercadoria de maior valor, em detrimento daquelas desprovidas desses quesitos.

Considerando-se que a imensa maioria da população brasileira se encontra na base da pirâmide social, cuja renda salarial está nas menores faixas, é possível concluir que esse contingente está fadado a habitar os setores onde o valor da terra urbana condiz com seu poder aquisitivo. Nesse sentido, as camadas sociais de menor renda se instalam nas regiões "mais baratas", carecendo de inúmeros bens necessários para sua reprodução e mínima qualidade de vida urbana.

Martucci (1990, p. 16) distingue os termos casa, moradia e habitação, afirmando ser a casa o ente físico, do qual se apropria o ocupante, dando a ela o sentido de moradia, considerando-se os hábitos de uso da casa. No entanto, esse processo ocorre associado à inserção urbana, composta pelo atendimento da infraestrutura instalada e dos serviços urbanos, ampliando-se ao conceito de habitação. Habitar, portanto, representa o sentido mais amplo da ocupação do território urbano pelo cidadão e depende das características 
de localização: "quanto mais bem equipado estiver o setor urbano, no qual estiver localizada a casa, melhores serão as condições de uso da moradia, qualificando assim o produto habitação". Nesse contexto, é possível considerar que o conceito de habitação, não se estende de modo democrático a todo cidadão e sim aos grupos sociais que podem optar por viver em setores mais urbanizados.

Portanto, é necessário ponderar a questão da localização da terra urbana mais e menos valorizada nas cidades, afinal, as áreas centrais e suas imediações - ou centros expandidos - são, via de regra, aquelas mais equipadas e, consequentemente, supervalorizadas. Campos Filho (1999, p. 50) qualifica essa situação como um contrassenso, ao analisar que o cenário das cidades mais adensadas compreende centros urbanos sobrecarregados, bastante populosos, enquanto as periferias são rarefeitas, do ponto de vista de sua ocupação, e assim interpreta: "os dois exageros: excessiva verticalização nas áreas centrais e excessiva horizontalização das periferias urbanas".

Alencar (1999) comenta os fenômenos da expulsão e repulsão, quanto aos centros supervalorizados porém sobrecarregados, e afirma que há um extrato da população nessas cidades que desejaria habitar as áreas mais urbanizadas, ou centrais, onde se concentram as maiores taxas de oportunidades de trabalho, além da diversidade de serviços oferecidos. Entretanto, representam as camadas sociais menos favorecidas e incapazes de custear esse tipo de moradia, sendo "expulsas" para regiões urbanas periféricas, economicamente mais acessíveis. Por outro lado, os grupos que poderiam arcar com os valores excessivos do solo, nesses centros supervalorizados, "repudiam" os efeitos do inchaço urbano, entre outros, escassez de abastecimento nas redes de infraestrutura, congestionamentos viários e de transportes coletivos e poluição ambiental e optam por viver em locais isolados desses "sintomas". 
O grande propósito de uma preocupação constitucional com a política urbana, dentro do título Da ordem econômica e financeira, e como se conclui pela breve leitura dos artigos 182 e 183, é a interligação e interdisciplinaridade entre o aspecto urbano da cidade e outros vieses, como a política, o social e o econômico. $\mathrm{O}$ fato de a latitude urbana estar inserida no título da ordem econômica já bem demonstra que esta não poderá ser bem-sucedida sem o respeito que deve à própria cidade. $\mathrm{O}$ desenvolvimento estrito é predatório, contaminando o cerne social e arruinando as bases que outrora propiciaram a ascensão econômica. Daí a razão pela qual a propriedade privada não se basta, se não for para promover sua função social.

A cidade e o urbano não podem ser compreendidos sem as instituições oriundas das relações de classe e de propriedade. Ela mesma, a cidade, obra e ato perpétuos, dá lugar a instituições específicas: municipais. As instituições mais gerais, as que dependem do Estado, da realidade e da ideologia dominante, têm sua sede na cidade política, militar, religiosa. Elas aí coexistem com as instituições propriamente urbanas, administrativas, culturais. Motivo de certas continuidades notáveis através das mudanças da sociedade (Lefebvre, 2011, p. 59; grifo no original).

Desse prisma, é notório que há um processo de segregação socioespacial nas cidades brasileiras, que consolida o sentido de mercadoria ao solo urbano e, consequentemente, a renda que o mesmo promove aos grupos que se beneficiam da lógica desse mercado. Harvey (1996) exemplifica de modo pragmático esse fato quando aborda o valor de uso e o valor de troca que a propriedade urbana possui. Na condição de uso, o território da cidade tem valor imensurável, posto que se trata de uma necessidade básica do cidadão; concomitantemente, o mercado imobiliário comercializa essa mercadoria tendo, como base, seu valor de troca. 
Observa-se, portanto, que a dinâmica das transformações no solo urbano ocorre por indução, ainda que haja manifestações espontâneas de uso e ocupação através de atos irregulares enquanto soluções emergenciais decorrentes da primordialidade de se "viver no urbano". Maricato (2001, p. 16) menciona que tais manifestações promovem um "gigantesco movimento de construção de cidade", imbuído do atendimento às necessidades de sobrevivência da população, e "bem ou mal, de algum modo, improvisado ou não", esses habitantes moram em cidades.

Bonduki e Rolnik (1982) propõem a leitura dessa conduta na ocupação das cidades analisando a indiscriminada utilização do termo periferia, da perspectiva geográfica que representa o território distante dos centros e, sociológica, configurada pela reprodução da força de trabalho. Conclui-se que ocorre a periferização como mecanismo de expansão urbana, seguindo-se vetores predeterminados ou não; contudo, esse evento pode estar vinculado à condição socioeconômica dos habitantes. Indubitavelmente, o termo periferia necessita ampla análise e merece um olhar cuidadoso enquanto fenômeno urbano.

É bem verdade que, assim como este, outros fenômenos presentes nas cidades brasileiras representam desafios crescentes às gestões públicas. Curiosamente, ainda que gerem debates calorosos como o da reforma urbana, perpetuam consequências previsíveis. A exemplo, apontam-se as ocupações irregulares em áreas ambientalmente frágeis; os vazios urbanos que, em muitos casos, impõem deslocamentos desnecessários aos cidadãos e a degradação de ambientes urbanos, que serão debatidos mais adiante.

Alguns instrumentos legais estabelecem parâmetros mínimos de ocupação em áreas ambientalmente frágeis, como as próximas a cursos hídricos - rios, represas, nascentes -, buscando controlar os impactos causados pela ação humana. No entanto, são também elementos balizadores para a prática do "direito à cidade", tendo em vista que as 
áreas preservadas constituem bens públicos, quais sejam, propriedades de todos.

O direito à cidade é, antes de tudo, uma compreensão global do processo urbano de formação e crescimento. Sob outro aspecto, como ressalta Harvey (2014), a propósito de Lefebvre, o direito à cidade é uma queixa e uma exigência. A queixa enquanto resposta a uma "dor existencial de uma crise devastadora da vida cotidiana na cidade". E a exigência enquanto impulsionadora da busca de uma "vida urbana alternativa que fosse menos alienada, mais significativa e divertida", ao mesmo tempo que "conflitante e dialética, aberta ao futuro, aos embates [...] e à eterna busca de uma novidade incognoscível” (Harvey, 2014, p. 11).

Carlos (1994, p. 88) reitera esse direito focalizando o papel dos movimentos sociais:

É a luta pela cidadania, a luta por transformações socioeconômico-espaciais. Trata-se, de fato, do inalienável direito a uma vida decente para todos, não importando o lugar em que se encontre, na cidade ou no campo. Mais do que um direito à cidade, o que está em jogo é o direito a obter da sociedade aqueles bens e serviços mínimos, sem os quais a existência não é digna. É o direito à participação numa sociedade de excluídos.

Não por acaso, a leitura do próprio artigo 182 da Constituição federal explicita:

A política de desenvolvimento urbano, executada pelo Poder Público municipal, conforme diretrizes gerais fixadas em lei, tem por objetivo ordenar o pleno desenvolvimento das funções sociais da cidade e garantir o bem-estar de seus habitantes.

A despeito de preocupações anteriores, como ressalta Leal (2013, p. 1.864), fora a Constituição de 1988, 
que dera "atenção à matéria urbanística, com dispositivos sobre as diretrizes do desenvolvimento urbano, preservação ambiental, planos urbanísticos e função social da propriedade", encontrando-se a competência para o "desenvolvimento adequado do sistema de cidades" no artigo 21, parágrafo XX, e o "desenvolvimento urbano no território municipal" no artigo 182, o estudo do chamado direito à cidade faz nascer a percepção de que, na realidade, tal direito se perfaz em um conjunto de direitos que necessitam ordenação para manter em termos urbanísticos a própria cidade. Logo, a falha em qualquer um dos setores jurídicos provoca um desalinhamento na lógica da cidade estruturada e equilibrada, melhor dizendo, a cidade sustentável. Castilho (2010, p. 18) interpreta a vertente do direito urbanístico ${ }^{2}$ "que constitui a face jurídica do urbanismo" e que estabelece "critérios de análise das normas e institutos que disciplinam a ordenação dos espaços habitáveis", visando-se o equilíbrio urbano.

A compreensão de que às cidades está intrínseco o desempenho de diferentes funções pelo cidadão pode ser observada na teoria e história da arquitetura e urbanismo, particularmente nas proposições do Movimento Moderno. A Carta de Atenas ${ }^{3}$ aponta as funções da cidade - habitação, trabalho, recreação e circulação - consideradas básicas ao cotidiano urbano. Numa visão holística do território urbano, palco das diversas atividades em dinâmica constante, torna-se imperioso a instituição de mecanismos de gestão e monitoramento das transformações urbanas, como os instrumentos de planejamento urbano.

\footnotetext{
2 O autor prossegue citando a definição desse ramo jurídico por Ramón Parada: "Direito Urbanístico é o conjunto de normas reguladoras dos processos de ordenação do território e sua transformação física por intermédio da urbanização e da edificação."

3 Documento firmado entre profissionais da arquitetura e urbanismo como conclusão do CIAM (Congresso Internacional de Arquitetura Moderna) de 1933, realizado em Atenas, Grécia.
} 
No entanto, entenda-se esse planejamento como um processo, com continuidade assegurada, desvinculado de interesses político-partidários que intentem manipular a paisagem urbana e os bônus que a renda do solo urbano pode garantir. Em um contexto dessa natureza, diretrizes multidisciplinares regulam ações e consequências das ocupações urbanas e, mormente, reconhecem a cidade "real" contendo a parcela urbana devidamente regularizada, somada às regiões constituídas pela ilegalidade, fato bastante comum nas metrópoles.

Assim, a cidade que se escora em um processo de planejamento urbano sólido, que resulte em excelentes vias de tráfego, adequado Plano Diretor e em divisão territorial razoável, mas não goza de espaços públicos destinados à preservação ambiental (artigos $7^{\circ}$ a 21 da Lei n ${ }^{\circ}$ 9.985/2000 - Sistema Nacional de Unidades de Conservação da Natureza), estará em débito com o necessário equilíbrio que o direito à cidade exige para que a população tenha uma vida digna, com lazer, saúde, bem-estar, alimentação, trabalho, entre outros itens imprescindíveis à vivência social. Da mesma forma, a cidade que se faz poluída ambiental e/ou visualmente não está em consonância com as diretrizes da sua coletividade no tocante ao direito a uma cidade hígida ${ }^{4}$.

\footnotetext{
4 A despeito das chamadas "Leis da Cidade Limpa", difundidas com a Lei paulistana $\mathrm{n}^{\circ} 14.223 / 2006$, elaborada a partir de estudos da arquiteta e urbanista Regina Monteiro, cuja proposta se estendeu a inúmeros municípios brasileiros. De acordo com referida legislação, em seu artigo $3^{\circ}$, a ordenação da paisagem em São Paulo objetiva o atendimento ao interesse público em consonância com os direitos fundamentais da pessoa e as necessidades de conforto ambiental, com a melhoria da qualidade de vida urbana, promovendo: o bem-estar estético, cultural e ambiental da população; a segurança das edificações e da população; a valorização do ambiente natural e construído; a segurança, a fluidez e o conforto nos deslocamentos de veículos e pedestres; a percepção e a compreensão dos elementos referenciais da paisagem; a preservação da memória cultural; a preservação e a visualização das características peculiares dos logradouros e das fachadas; a preservação e a visualização dos elementos naturais tomados em seu conjunto e em suas peculiaridades ambientais nativas; o fácil acesso e utilização das funções e serviços de interesse coletivo nas vias e logradouros; o fácil e rápido acesso aos serviços de emergência, tais como bombeiros, ambulâncias e polícia; o equilíbrio de interesses dos diversos agentes atuantes na cidade para a promoção da melhoria da paisagem do Município.
} 
Em sentido análogo, o fenômeno dos vazios urbanos, apontado anteriormente, presente na imensa maioria das cidades brasileiras, pode ser considerado elemento preponderante na configuração do tecido urbano, uma vez que interrompe a continuidade da malha viária e o assemelha a uma "colcha de retalhos" (Campos Filho, 1999, p. 54):

A retenção de terrenos nas zonas urbanas das cidades brasileiras atinge um valor em que dificilmente se pode acreditar [...] como aproximadamente a metade ou mais do espaço urbano brasileiro, nas médias e grandes cidades, está vazio, o cidadão que nelas habita anda, em média, pelo menos o dobro das distâncias que deveria andar, caso tais vazios inexistissem. Assim também o poder público é obrigado a pelo menos dobrar o seu investimento e o custeio das redes de serviços públicos, que dependem da extensão da cidade.

Semelhantemente às ações mitigadoras das ocupações irregulares em áreas ambientalmente frágeis, as administrações públicas brasileiras lidam com o impasse dos vazios urbanos por meio de penalidades, que redundam no incentivo ao uso e à ocupação contínua do tecido urbano, o que será abordado na seção referente ao Estatuto da Cidade.

O direito à cidade é fruto de uma ambição coletiva, com raiz na seara dos direitos humanos, e que visa se sobrepor à lógica liberal - ou neoliberal - em que predominam o direito de propriedade privada, puro e simples, e a taxa de lucros acima dos direitos essenciais para a vida da própria sociedade (Harvey, 2014, p. 27).

Não há como negar a cidade como exteriorização do elemento humano e eterna criação e recriação do homem acerca do seu próprio papel na sociedade. Melhor dizendo, a cidade é o desejo materializado do homem enquanto parte de uma sociedade que também deseja se materializar no mesmo ambiente. 
Reivindicar o direito à cidade no sentido que aqui proponho equivale a reivindicar algum tipo de poder configurador sobre os processos de urbanização, sobre o modo como nossas cidades são feitas e refeitas, e pressupõe fazê-lo de maneira radical e fundamental (Harvey, 2014, p. 30).

Nesse jogo de equilíbrios, os constituintes contemporâneos viram por bem desenhar contornos jurídicos que aceitassem o capital privado, mas, ao mesmo tempo, destinasse-lhes algumas obrigações em prol do todo. O maior desses exemplos é, quiçá, a função social da propriedade, a indicar que a propriedade não constitui fim em si mesma, mas apenas se for voltada para algum proveito social. Isto é, apenas se desempenhar uma função que auxilie o próprio desenvolvimento da sociedade. Com muito mais ênfase, quando falamos da propriedade que se volta a objetivos econômicos.

Na Constituição alemã, por exemplo, o artigo 14.2 afir94 ma que a "propriedade obriga. Seu uso deve servir, ao mesmo tempo, ao bem comum”. Nota-se uma clara tendência das Constituições contemporâneas a uma nova leitura do privado inserido em um contexto público. Como ressaltam Mendes, Coelho e Branco (2008, p. 1.358), a exigência constitucional no tocante ao direito de propriedade é "um postulado que configura, sem sombra de dúvida, a mais radical contraposição ao dogma individualista que reputava sagrado o direito de propriedade e assegurava ao seu titular, em termos absolutos, o poder de usar, gozar e dispor dos seus bens", "sem nenhuma preocupação de caráter social".

Não por acaso, a expressão função social da propriedade é exposta em quatro ocasiões em nossa Constituição: artigos $5^{\circ}$, XXIII; 170, 182, $\$ 2^{\circ}$; e 186, caput, enfatizando que a propriedade "não é mero direito privado, e sim uma instituição voltada ao cumprimento de uma função social" (Bulos, 2010, p. 592).

E nossa Carta também obriga. Tanto que se vale de medidas para garantir que a função social da propriedade 
seja cumprida, desde a criação de alíquotas progressivas de IPTU no imóvel urbano até, num derradeiro momento, à desapropriação, com pagamento com títulos da dívida pública, em um extenso prazo de dez anos (art. 182, § $4^{\circ}$ ). Para os imóveis rurais - a título elucidativo - o prazo chega a vinte anos (art. 184, caput).

$\mathrm{Na}$ interpretação dos dispositivos, o Supremo Tribunal Federal destaca, por exemplo, que é inerente à função social da propriedade: (a) a utilização adequada dos recursos naturais e a preservação do meio ambiente (MS $n^{\circ}$ 22.164, rel. Min. Celso de Mello); (b) a utilização correta do direito de edificar $\left(\mathrm{RE} \mathrm{n}^{\circ} 178.836\right.$, rel. Min. Carlos Velloso); (c) a possibilidade de o poder público estabelecer ordenação física e social da ocupação do solo da cidade, principalmente em atividades de risco, ainda que já exista licença concedida ( $\mathrm{RE} \mathrm{n}^{\circ}$ 235.736, rel. Min. Ilmar Galvão).

Em termos urbanos, a hermenêutica constitucional, mormente na interpretação de leis como o Estatuto da Cidade (Lei $\mathrm{n}^{\circ} 10.257 / 2001$ ), a partir dos artigos 182 e 183 da Constituição federal, tem o escopo de encontrar a leitura que efetive as providências necessárias para que a cidade se beneficie das funções indispensáveis à sua manutenção equilibrada e sustentável ${ }^{5}$. E, por via de consequência, repassar esse direito, numa terceira dimensão, ao seu cidadão, na posição de um direito à cidade ${ }^{6}$.

O direito à cidade é, para além de suas propostas, uma promessa duradoura. Uma promessa de que, no futuro, as

\footnotetext{
5 Não por acaso, a primeira diretriz geral da política urbana, consoante o Estatuto da Cidade: "garantia do direito a cidades sustentáveis, entendido como o direito à terra urbana, à moradia, ao saneamento ambiental, à infraestrutura urbana, ao transporte $\mathrm{e}$ aos serviços públicos, ao trabalho e ao lazer, para as presentes e futuras gerações".

6 "Política urbana é o conjunto de providências que objetivam ordenar os espaços habitáveis, organizando todas as áreas em que o ser humano exerce funções sociais indispensáveis à sua sobrevivência, isto é, habitação, trabalho, recreação (lazer) e circulação. Visa, a um só tempo, proporcionar melhoria das condições de vida do homem na comunidade" (Bulos, 2010, pp. 1.496-97).
} 
próximas gerações também vão poder usufruir do mesmo direito a um sistema urbano equilibrado e sustentável, e mais, em condições melhores dos que as atuais.

Como ressalta Lefebvre (2011, p. 138):

A realização da sociedade urbana exige uma planificação orientada para as necessidades sociais, as necessidades da sociedade urbana. Ela necessita de uma ciência da cidade (das relações e correlações na vida urbana). Necessárias, estas condições não bastam. Uma força social e política capaz de operar esses meios (que são mais do que meios) é igualmente indispensável.

Nas metrópoles, urge ainda o desafio dessa proposta não se individualizar, no sentido do direito à cidade como um direito de cada um, mas enquanto um direito de terceira dimensão, de cunho metaindividual, como já 96 expusemos aqui. É que, como ressalta Simmel (1973, p. 23), as grandes cidades têm a peculiar característica de individualizar a pessoa, principalmente porque "o desenvolvimento da cultura moderna é caracterizado pela preponderância do que se poderia chamar de o 'espírito objetivo' sobre o 'espírito subjetivo'”, seja no âmbito jurídico ou social. Nesses locais, além das próprias questões urbanas, é preciso contemplar a socialização do direito à cidade, para que os indivíduos não a sintam como sua, mas como nossa.

Muito disso, como ressalta Harvey (2012, p. 25), decorre de incontáveis forças urbanas e movimentos urbanos sociais, mas que apenas podem se tornar postulantes de grandes mudanças quando unidos em torno de ideais comuns, independentemente do conteúdo do direito à cidade descrito em lei.

A parte jurídica do direito à cidade é, por assim dizer, apenas a ponta do iceberg. Muito além, os artigos 
182 e 183 da Constituição federal, bem como o Estatuto da Cidade, são hábeis fontes de diretrizes e de previsão instrumental, mas o direito à cidade perpassa um núcleo muito mais político, social e antropologizador do que propriamente jurídico.

No que concerne aos instrumentos legais que dispõem sobre o direito à cidade, por intermédio do controle urbanístico e códigos de conduta do cidadão no ambiente urbano, observa-se: por um lado, o seu amplo sentido institucional, na medida em que direcionam novos processos de uso e ocupação do solo, e, por outro, o modo como influenciam as ações coletivas na cidade. Roméro e Bruna (2010, p. 20) se debruçam sobre os instrumentos da política do meio ambiente nas metrópoles e salientam que

[...] na ordenação das aglomerações urbanas, usos e costumes são cada vez mais importantes, pois podem significar intenções morais e deveres de Estado, então abrangendo a gestão e a consciência do ato administrativo para as comunidades.

Lefebvre (2011, p. 108) completa:

Portanto, é na direção de um novo humanismo que devemos tender e pelo qual devemos nos esforçar, isto na direção de uma nova práxis e de um outro homem, o homem da sociedade urbana.

Embora sejam veladas as nuances da força política no manejo das cidades, orquestrado por agentes produtores dos vetores de expansão urbana, promotores da desigualdade e exclusão socioespacial, entre inúmeras ações predatórias do ambiente natural e do construído, as mobilizações em prol da reforma urbana no Brasil não cessam. 


\section{0 estatuto da cidade e seus instrumentos por um "novo urbano"}

No limiar deste século, o Estatuto da Cidade, como é conhecida a Lei federal $\mathrm{n}^{\circ} 10.257 / 2001$, proclamou o subsídio às administrações públicas municipais, em todo o território brasileiro, para o enfrentamento das "mazelas urbanas", por se tratar de um documento norteador da aplicabilidade de instrumentos urbanísticos eficazes. Em seu conteúdo, nota-se o reflexo da diversidade de fenômenos existentes nas cidades brasileiras, timidamente sinalizados nos artigos 182 e 183 da Constituição federal, já aqui analisados.

O intervalo de onze anos entre a Carta Constitucional e a aprovação do Estatuto foi notadamente marcado por intensos debates, negociações e arranjos sobre a política urbana nacional e resultou na coletânea de instrumentos inovadores, na visão de Rolnik (2001, p. 5; grifo no original):

As inovações contidas no Estatuto situam-se em três campos: um conjunto de novos instrumentos de natureza urbanística voltados para induzir - mais do que normatizar - as formas de uso e ocupação do solo; uma nova estratégia de gestão que incorpora a ideia de participação direta do cidadão em processos decisórios sobre o destino da cidade e a ampliação das possibilidades de regularização das posses urbanas, até hoje situadas na ambígua fronteira entre o legal e o ilegal.

Sobrepondo-se o trecho "voltados para induzir - mais do que normatizar - as formas de uso e ocupação do solo" à colocação anterior de Roméro e Bruna (2010), reforça-se a perspectiva de inferência que possui o Estatuto, na produção e reprodução do espaço urbano. A título analítico, propõe-se focalizar os três campos apontados por Rolnik (2001), alinhando-se potencialidades e polêmicas da disciplina urbanística dessa Lei, em torno da problemática dos fenômenos urbanos discutidos neste artigo. 


\section{A aplicabilidade dos novos instrumentos de urbanísticos do Estatuto da Cidade}

O "Capítulo II - Dos Instrumentos da Política Urbana" do Estatuto, na Seção I, direciona as escalas territoriais a que se propõem os instrumentos apontados pela Lei, em se tratando de planos de ordenação do território e de desenvolvimento nas esferas nacional, estadual e regional. Na sequência, estabelecem-se as intenções de planejamento territorial nas abrangências de regiões metropolitanas e outras formas de configuração regional propostas pela Constituição federal de $1988^{7}$, bem como nos municípios. É oportuno refletir sobre a vulnerabilidade que, atualmente, essa organização territorial contemplada pela Lei possui diante de processos de urbanização dispersa, principalmente ao longo de eixos viários intermunicipais e interestaduais, o que tem resultado em novas centralidades.

Por esse prisma, o enfoque dos planos e outros documentos que dispõem sobre o planejamento necessita de maior aprofundamento das realidades de que tratam, objetivando o controle de uso e ocupação de núcleos urbanizados em geral, quais sejam as escalas de abrangência. Inegavelmente, os movimentos migratórios e pendulares que ocorrem entre cidades que "polarizam" e "são polarizadas" constituem dados indispensáveis na formulação de diagnósticos de planejamento.

No tocante à "improdutividade" da terra urbana apreciada anteriormente, a qual tem resultado, em especial, na configuração de processos de urbanização excludentes, e reforçado o valor de troca do espaço-mercadoria, observa-se que o instrumento intitulado "Parcelamento, Edificação ou Utilização Compulsórios" contempla o cumprimento da

\footnotetext{
7 As formas de organização regional em questão são: regiões metropolitanas, aglomerados urbanos e microrregiões, previstas no artigo 25 da nossa Constituição (Capítulo III - Dos Estados Federados).
} 
função social da propriedade urbana como prerrogativa da ocupação e uso adequado dos imóveis urbanos.

A retenção especulativa de um estoque de imóveis nas cidades brasileiras acentua a prática da segregação socioespacial, uma vez que blinda áreas urbanizadas e com crescente valor de troca, definindo discriminadamente quais são as possibilidades de instalação da população de menor renda nessas cidades. Por meio desse instrumento, as gestões municipais têm possibilidades de intervir junto à propriedade urbana subutilizada e impulsionar sua produtividade.

O corolário, em casos de descumprimento de tal instrumento, é a tributação gradativa sobre os imóveis improdutivos, através do IPTU (Imposto Predial Territorial Urbano) progressivo no tempo, agravado por processos de desapropriação, o que demonstra evidente rigor no fomento ao uso e à ocupação do solo, com foco no atendimento às "necessidades comunitárias e sociais demarcadas pelo Plano Diretor, vinculado este 100 que está à melhoria da qualidade de vida digna das pessoas que nela vivem” (Leal, 2013, p. 1.874). Os vazios urbanos, fatalmente, constituem um fenômeno vislumbrado por esses instrumentos, objetivando-se a continuidade do tecido urbano, seu adensamento e a otimização dos recursos existentes de infraestrutura e serviços.

Outro fenômeno característico de imóveis subutilizados nas cidades são as áreas degradadas ou deterioradas, considerando-se que existem definições específicas para tais termos ${ }^{8}$. As áreas urbanas centrais, comumente compostas por edificações e outros elementos representativos à história e identidade locais, áreas portuárias ou contíguas a terminais de transporte, enfim, cujo uso é intenso

\footnotetext{
8 Vargas e Castilho (2006) especificam o caráter da deterioração como um processo de perda da qualidade dos espaços físicos, vitimados por depredação, abandono, relegados pelo proprietário, diferentemente do conceito de degradação, que agrega a supressão do valor social, e, portanto, reverbera um contínuo processo de negativa por parte da sociedade.
} 
apenas em turnos específicos, são bastante suscetíveis à utilização desses instrumentos do Estatuto.

Possuem natureza congênere o "Direito de Superfície" e "Direito de Preempção" no contexto do cumprimento da função social da propriedade urbana, pois, uma vez subutilizada, no caso dos vazios, pode-se conceder o direito de uso e ocupação de sua superfície, além de conferi-lo, preferencialmente, ao poder público. Diante do quadro deficitário de assentamentos habitacionais no Brasil, especialmente no desprovimento de áreas urbanizadas aos conjuntos destinados à população de menor renda, ambos os instrumentos consolidam mais uma alternativa à solução dos fenômenos dos vazios urbanos e da periferização.

O vertiginoso processo de urbanização nas cidades brasileiras, como se sabe, não ocorreu concomitantemente à implantação de instrumentos de planejamento urbano e, por consequência, identificam-se variados impactos causados pelo adensamento desordenado dos centros urbanos. As demandas pela utilização das redes de infraestrutura e de serviços nessas cidades tornaram-se um ônus representativo ao ambiente urbano e seus habitantes, bem como às administrações públicas. Esse adensamento se dá, essencialmente, em decorrência do fenômeno da verticalização exacerbada, comprometendo, portanto, itens existentes para o abastecimento de imóveis que, subitamente, passam a ser ocupados por um número muitas vezes maior de domicílios.

A “Outorga Onerosa do Direito de Construir" reputa-se, desse modo, um instrumento eficiente no controle da verticalização e justo meio de aferir os ônus ora comentados àqueles que promovem os impactos por ela causados. Se há maior lucratividade na construção de imóveis, mais onerosos serão os investimentos daqueles que serão beneficiados, possibilitando-se a reversão desses valores em melhorias às redes e serviços sobrecarregados. Não obstante, é válido ressaltar que todos os instrumentos que implicam necessaria- 
mente em taxação ao cidadão redundam na autonomia dos gestores desses recursos, no que diz respeito à arrecadação, guarda e aplicação dos mesmos.

Mais ainda, é possível até mesmo o condicionamento da licença de construção ou funcionamento à realização de obras no entorno do empreendimento, minimizando, desde então, os impactos negativos que possam trazer ao aspecto urbano. Haja vista o Estudo de Impacto de Vizinhança, outro instrumento previsto pela Lei, cujo fito é antever as possíveis consequências que a implantação de um empreendimento de natureza complexa pode trazer às suas imediações. Dentre os quesitos a serem observados, estão: adensamento populacional, geração de tráfego e demanda por transporte público, ventilação e iluminação, e valorização imobiliária.

\section{Participação na gestão das cidades e regularização na "cidade real"}

102 Assim como o aludido por Rolnik (2001), um novo enfoque fora dado à gestão urbana pelo Estatuo da Cidade, uma vez que se revela a Gestão Democrática da Cidade, embora a participação popular na época - e ainda hoje, é válido salientar - fosse bastante singela, evidenciada em circunstâncias estanques de manifestações desvencilhadas dos ideais presentes nos debates sobre a política urbana brasileira.

Em que pese o cenário brasileiro estivesse em fase embrionária da prática democrática, o Estatuto abordou recursos para que as administrações municipais garantissem a ciência e o envolvimento dos cidadãos nas questões urbanas. Nesse sentido, para que se garantisse a participação popular nessa gestão, a lei define a instituição de órgãos colegiados de política urbana, audiências públicas e a possibilidade da emergência de projetos e planos por iniciativa popular.

Por derradeiro, cumpre destacar ainda o esforço dispendido na regularização fundiária. Apesar de seus instru- 
mentos, nota-se certa timidez no referido processo, passados quase quinze anos de vigor do Estatuto da Cidade.

A irregularidade fundiária, infelizmente, é um processo comum nas cidades brasileiras, fruto do crescimento urbano desordenado e da falta de preocupação, até recentemente, com esse desenvolvimento. De certo, a regularização é instituto jurídico-urbanístico que coaduna com o desenvolvimento sustentável da cidade, com impactos diretos no meio ambiente e até mesmo na economia.

A manutenção da desordem "ilegal" na urbanização brasileira, por outra via, é uma ofensa aos próprios princípios orientadores da política urbana, ao mesmo tempo que funcionam como elementos propiciadores de desigualdades sociais, gerando verdadeiros apartheids urbanos.

Evidentemente que, em grandes centros, a perquirição de soluções milagrosas não coaduna com os incontáveis problemas urbanos, mas, de certo, no mínimo, o que se deve é impedir a reprodução do status quo naquilo que for novo e, gradativamente, buscar implementar a regularização fundiária por meio de novas diretrizes de zoneamento urbano.

\section{$* * *$}

É razoável considerar que a política urbana brasileira está contemplada nos artigos 182 e 183 da Constituição federal de 1988, assim como foi regulamentada pelo Estatuto da Cidade, de 2001. Todavia, é pertinente questionar: quão efetiva é a práxis dessa política nas cidades brasileiras?

Ainda que o Estatuto tenha subsidiado consistentemente as administrações municipais, por meio de instrumentos urbanísticos efetivos no enfrentamento das "mazelas urbanas", pouco se constata a respeito do cumprimento da função social da propriedade urbana. Conclui-se, portanto, que tampouco o respaldo legal desses documentos tem sido capaz de assegurar o "direito à cidade". 
Em primeiro lugar, insta salientar que uma nítida preocupação urbana apenas adveio com a Constituição federal de 1988, e, após isso, foram mais de onze anos para uma primeira tentativa de tornar práticos os instrumentos vocacionados a tanto.

Hoje, passados mais de quinze anos do Estatuto da Cidade, no entanto, o que se vislumbra na prática anda muito aquém dos objetivos constituintes e, num segundo momento, das tentativas de realização dos legisladores.

Questões com a regularização fundiária, por exemplo, em grandes centros parecem ter sofrido recrudescimento.

Outros instrumentos, no entanto, como a Gestão Democrática da Cidade e o Estudo de Impacto de Vizinhança, aliados às preocupações ambientais, têm se aprimorado, ajustando-se em termos reais em consonância com os objetivos que conformam o direito à cidade: uma constante e gradativa busca de tornar a cidade um ambiente equilibrado,

104 em todos os níveis, de forma que propicie ao cidadão a justa qualidade de vida urbana.

\section{Danila M. de Alencar Battaus}

é professora e pesquisadora da Universidade de Marília, São Paulo, com pós-doutorado pelo Instituto de Arquitetura e Urbanismo da USP.

\section{Emerson Ademir B. de Oliveira}

é advogado e professor assistente na graduação e mestrado em Direito da Universidade de Marília, São Paulo; mestre e doutor pela USP, e pós-doutorando na Universidade de Coimbra, de Portugal.

\section{Bibliografia}

ALENCAR, D. M. 1999. Consolidação de conjuntos habitacionais de caráter social através de serviços urbanos e infraestrutura urbana. Dissertação de mestrado. São Carlos: EESC-USP. 
ANDRADE, J. C. V. de. 1998. Os direitos fundamentais na Constituição Portuguesa de 1976. Coimbra: Almedina.

BONAVIDES, P. 2002. Curso de direito constitucional. São Paulo:

Malheiros.

BONDUKI, N.; ROLNIK, R. 1982. "Periferia da Grande São Paulo: reprodução do espaço como expediente de reprodução da força de trabalho". In: MARICATO, E. (org.). A produção capitalista da casa (e da cidade) do Brasil industrial. São Paulo: Alfa-Ômega.

BULOS, U. L. 2010. Curso de direito constitucional. São Paulo: Saraiva.

CAMPOS Filho, C. M. 1999. Cidades brasileiras: seu controle ou o caos. São Paulo: Studio Nobel.

CANOTILHO, J. J. G. 2007. Direito constitucional e teoria da constituição. Coimbra: Almedina.

CARLOS, A. F. A. 1994. A cidade. São Paulo: Contexto.

CASTILHO, J. R. F. 2010. Disciplina urbanística da propriedade: o lote e seu destino. São Paulo: Pillares.

HARVEY, D. 1996. "Espaços urbanos na 'Aldeia Global': reflexões sobre a condição urbana no capitalismo no final do século XX”. Cadernos de Arquitetura e Urbanismo, Belo Horizonte, PUC-Minas, n. 4, pp.171-89. . 2012. "O direito à cidade". Lutas sociais, São Paulo, n. 29, pp.73-89. 2014. Cidades rebeldes: do direito à cidade à revolução urbana. São Paulo: Martins Fontes.

LEAL, R. G. 2013. "Comentário ao artigo 182". In: CANOTILHO, J. J. G. et al. (coords.). Comentários à Constituição do Brasil. São Paulo: Saraiva/Almedina.

LEFEBVRE, H. 2011. O direito à cidade. 5. ed. São Paulo: Centauro.

MARICATO, E. 2001. Brasil, cidades: uma alternativa para a crise urbana. Petrópolis, RJ: Vozes.

MARTUCCI, R. 1990. Projeto tecnológico para edificações habitacionais: utopia ou desafio?. Tese de doutorado. São Paulo: FAU-USP.

MENDES, G. F.; COELHO, I. M.; BRANCO, P. G. G. 2008. Curso de direito constitucional. São Paulo: Saraiva.

ROLNIK, R. 2001. "Estatuto da Cidade - Instrumento para as cidades que sonham crescer com justiça e beleza”. In: SAULE Júnior, N.; ROLNIK, R. Estatuto da Cidade: novas perspectivas para a reforma urbana. São Paulo: Pólis.

ROMÉRO, M. A.; BRUNA, G. C. 2010. Metrópoles e o deságio urbano frente ao meio ambiente. São Paulo: Blucher.

SARLET, I. W. 2001. A eficácia dos direitos fundamentais. Porto Alegre: Livraria do Advogado. 
0 direito à cidade: urbanização excludente e a política urbana brasileira

SIMMEL, G. 1973. "A metrópole e a vida mental”. In: VELHO, O. G. (org.). O fenômeno urbano. Rio de Janeiro: Zahar.

VARGAS, H. C.; CASTILHO, A. L. H. (orgs.). 2006. Intervenções em centros urbanos. São Paulo: Manole. 


\section{O DIREITO À CIDADE: URBANIZAÇÃO EXCLUDENTE E A POLÍTICA URBANA BRASILEIRA}

DANILA M. DE ALENCAR BATTAUS

\section{EMERSON ADEMIR B. DE OLIVEIRA}

Resumo: O propósito deste artigo é realizar uma reflexão acerca do direito à cidade conforme os princípios de política urbana estabelecidos na Constituição federal de 1988 e nos instrumentos dela decorrentes por meio do Estatuto da Cidade. O direito à cidade, enquanto direito metaindividual, decorre da preocupação legal em se propiciar ao cidadão um ambiente urbano equilibrado, hígido e harmônico. Mas será que nossos instrumentos, dispostos a tanto, estão cumprindo seu papel?

Palavras-chave: Política Urbana; Direito à Cidade; Instrumentos Legais; Exclusão Territorial.

\section{THE RIGHT TO THE CITY: EXCLUSIVE URBANIZATION AND THE BRAZILIAN URBAN POLICY}

Abstract: The purpose of this paper is to perform a reflection on the right to the city from the perspective of urban policy principles of the 88' Constitution, as well as the instruments that were created by the City Statute. The right to the city, while collective right, follows the legal concern to provide the citizen with a balanced, healthy and harmonized city. But does our instruments are fulfilling their role? Keywords: Urban Policy; Right to the City; Legal Instruments; Territorial Exclusion.

Recebido: 27/10/2015 Aprovado: 04/12/2015 